\title{
Total synthesis and functional characterization of Selenoneine
}

\author{
David Lim ${ }^{[a]}$, Dirk Gründemann ${ }^{[b]}$ and Florian P. Seebeck ${ }^{[a]^{*}}$
}

\begin{abstract}
The $N$ - $\alpha$-trimethyl 2-selenohistidine selenoneine is the selenium isolog of the natural antioxidant ergothioneine. Sulfur-toselenium substitutions are known to endow proteins and nucleic acids with special activities. In contrast, secondary metabolites that exploit selenium-specific chemistry are rare. Selenoneine therefore provides a unique opportunity to study how natural organoselenides interact with cellular processes. In this report we describe the chemical synthesis of selenoneine and other 2-selenoimidazoles. With synthetic selenoneine at hand we discovered a set of reactivities that distinguish selenoneine from ergothioneine, showing that the two compounds can fill distinct functional niches. Synthetic access to 2selenoimidazoles should pave the way to explore the pharmaceutical potential and physiological function of this heretofore inaccessible class of compounds.
\end{abstract}

Selenium is a critical micronutrient for humans. Too little or too much of it can cause disease, including depression, dementia, immune deficiency, hair loss or cardiovascular disease. ${ }^{[1]}$ Because selenium atoms have the same valency, electronegativity and almost the same size as sulfur atoms, many biosynthetic enzymes cannot efficiently distinguish between the two elements. ${ }^{[1 b]}$ As a result, most known selenium metabolites are isologs of the corresponding sulfur compounds including selenomethionine, selenocysteine, Se-adenosyl selenomethionine or selenobiotin. ${ }^{[16,2]}$ Their cellular concentration is largely dependent on the selenium content in the environment and their physiological purpose is unclear. ${ }^{[3]}$

In contrast, elaborate enzymatic machineries have evolved to enable targeted incorporation of selenium in the form of selenocysteine and 2-selenouridine into specific proteins and nucleic acids. ${ }^{[1 \mathrm{~b}, 4]}$ Specific sulfur-to-selenium substitutions can be advantageous because of the two elements show distinctly different reactivities. ${ }^{[1 \mathrm{c}]}$ For example, selenols are more acidic and more reducing that thiols $\left(\mathrm{p} K_{\mathrm{a}, \mathrm{SeH}}: \sim 5 ; \mathrm{p} K_{\mathrm{a}, \mathrm{SH}}: \sim 9\right){ }^{[5]}$ Selenols can efficiently react with triplet oxygen $\left({ }^{3} \mathrm{O}_{2}\right)$ whereas autoxidation of thiols usually depends on catalysis by transition metals. ${ }^{[6]}$ Although diselenide bonds are more stable than disulfide bonds, ${ }^{[7]}$ selenium generally forms

[a] Dr. D. Lim and Prof. Dr. F.P. Seebeck

Department for Chemistry

University of Basel

Mattenstrasse 24a, 4002, Basel, Switzerland

E-mail: florian.seebeck@unibas.ch

[b] Prof. Dr. Dirk Gründemann

Department of Pharmacology, University of Cologne, Faculty of Medicine and University Hospital Cologne, Gleueler Straße 24, 50931, Cologne, Germany

Supporting information for this article is given via a link at the end of the document.

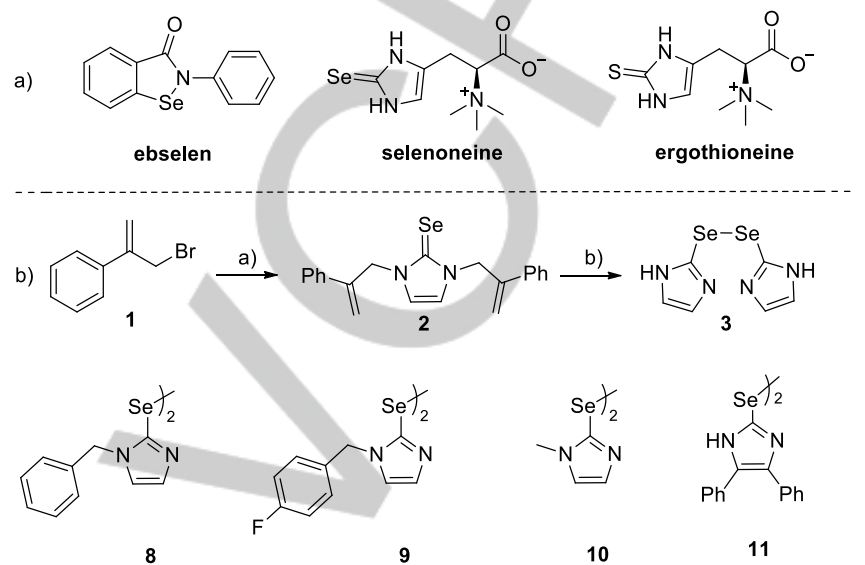

Figure 1. a) Chemical structures of ebselen, selenoneine and ergothioneine. b) Synthesis of 2-imidazole diselenide 3. Reaction conditions: a) 1) Imidazole, Nal, $\mathrm{K}_{2} \mathrm{CO}_{3}, \mathrm{DMF}, 16 \mathrm{~h}$; 2) Se, $\mathrm{K}_{2} \mathrm{CO}_{3}, \mathrm{DMF}, 80{ }^{\circ} \mathrm{C}, 16 \mathrm{~h} ; 53 \%$ yield; b) $1.7 \mathrm{M}$ tBuLi in hexane; THF, $-78{ }^{\circ} \mathrm{C}, 30$ mins, $94 \%$. Synthesis of 8-11 were performed using similar procedures. Overall yields over three steps: 8: $41 \%$; 9: $42 \%$; 10: $55 \%$; 11: $5 \%$

weaker bonds with period 2 elements, allowing selenium compounds to engage more readily in making and breaking covalent bonds. Because of this versatility selenium has also been included in the design of artificial enzymes, ${ }^{[8]}$ enzyme models, ${ }^{[9]}$ protein ligation strategies, protein folding studies, ${ }^{[10]}[7]$ or molecular probes. ${ }^{[11]}$ Furthermore, the observation that ebselen (Figure 1a) and other synthetic organoselenides can catalyse peroxide reduction and form covalent bonds to specific proteins highlighted the therapeutic potential of such compounds. ${ }^{[11 c, 12]}$ Indeed, a number of recent studies indicate that ebselen may be used in the treatment of a wide range of health problems. ${ }^{[13]}$

Surprisingly, there are very few examples of natural secondary metabolites that depends on selenium-specific chemistry for function. From such molecules one could learn how and where organoselenides - optimized by evolution - would interfere with cellular processes. ${ }^{[14]}$ One of these rare examples is selenoneine (Figure 1a). ${ }^{[15]}$ This selenium isolog of ergothioneine (Figure 1a) was first isolated from the muscle tissue of marine fish. ${ }^{[15-16]}$ Selenoneine also accumulates in humans with a seafood-rich diet which raises questions about potential health risks or benefits emanating from this unusual selenium source. ${ }^{[16-}$

17] However, aside of intriguing indications that selenoneine may provide protection against mercury poisoning, ${ }^{[16,18]}$ little is known about the chemistry of such compounds. ${ }^{[19]}$

In the quest of learning more, we developed the first chemical synthesis of unprotected 2-selenoimidazoles. Based on this 
WILEY-VCH<smiles>COC(=O)C(N)Cc1c[nH]cn1</smiles>

12

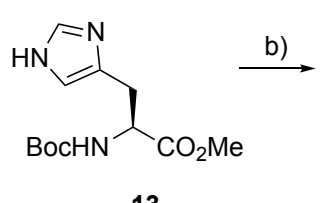

13<smiles>C=C(Cn1cc(CC(NC(=C)c2ccccc2)C(C)(C)C)c(=[Se])n1CC(=O)c1ccccc1)c1ccccc1</smiles>

14

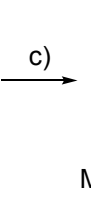

$\longrightarrow$<smiles>CC(=O)OC(C)(C)NC(Cc1c[nH]c([As])n1)C(C)=O</smiles>
15<smiles>C1C[Te]C1</smiles><smiles>[C-]1C=CC=C1</smiles><smiles>CCOC(=O)[Se]c1nc(C[C@H](NC(C)=O)C(C)=O)cn1C(=O)OCC</smiles>

17

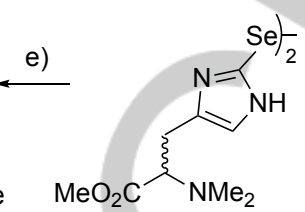

16<smiles>CN(C)C(=O)C(Cc1c[nH]c([Se]C[Se]c2nc(CC(C(=O)O)C(=O)O)c[nH]2)n1)C(=O)O</smiles>

20

Scheme 1. Total synthesis of selenoneine. Reaction conditions: a) 1) (Boc) ${ }_{2} \mathrm{O}$, trimethylamine, $\left.\mathrm{MeOH} ; 2\right) \mathrm{K}_{2} \mathrm{CO}_{3}, \mathrm{MeOH}$, reflux, $2 \mathrm{~h}, 76 \%$; b) 1) phenylallyl bromide, $\mathrm{K}_{2} \mathrm{CO}_{3}, \mathrm{Nal}, \mathrm{DMF}$; 2) Se, $\mathrm{K}_{2} \mathrm{CO}_{3}, 80^{\circ} \mathrm{C}, 81 \%$; c) $1.7 \mathrm{M} \mathrm{t}$-BuLi in hexane, THF, $-78{ }^{\circ} \mathrm{C}, 30$ mins, $100 \%$; d) 1) trifluoroacetic acid, triisopropylsilane, $\mathrm{DCM}$; 2) $\mathrm{CH}_{2} \mathrm{O}$, $\mathrm{NaCNBH}_{3}, \mathrm{MeOH}, 1 \mathrm{~h}, 53 \%$ over two steps; e) 1) $\mathrm{NaCNBH}_{3}, \mathrm{DCM}, 30$ mins; 2) triethylamine, ethylchloroformate, $10^{\circ} \mathrm{C}, 1 \mathrm{~h}, 31 \%$;) $\mathrm{Mel}, \mathrm{THF}, 16 \mathrm{~h}, 21 \%$; ) $\mathrm{LiOH} . \mathrm{H}_{2} \mathrm{O}, \mathrm{H}_{2} \mathrm{O}, 1 \mathrm{~h}, 100 \%$. Synthesis protocols and characterization of compounds are described in the supporting information.

methodology we synthesized selenoneine and characterized its properties in comparison with ergothioneine (Figure 1a).

Presently, the only available selenoimidazole derivative is $L$-selenoneine that is isolated either from marine fish or from fermented Schizosaccharomyces pombe. ${ }^{[20]}$ These sources are limited by low yields and restricted to the naturally occurring compound. Protocols to synthesize 2mercaptoimidazoles, including ergothioneine are well established, ${ }^{[21]}$ but these procedures invariably fail in the synthesis of 2-selenoimidazoles. A suggested synthesis of selenoneine proved irreproducible in our hands and others. ${ }^{[20 \mathrm{~b}}$, 22] Approaches that were devised to make $\mathrm{N}$-monosubstituted or $N, N$ '-disubstituted 2-selenoimidazoles are comparatively inefficient ${ }^{[9,23]}$ and impose narrow restrictions on the range of permissible $\mathrm{N}$-substituents.

A key challenge in the synthesis of unprotected 2selenoimidazoles stems from the vulnerability of the carbonselenium ( $\mathrm{C}-\mathrm{Se}$ ) bond towards harsh reductive and oxidative conditions. Hence, while alkylation of both nitrogen atoms is essential for attaching selenium to the imidazole ring, ${ }^{\text {[23a] }}$ conditions for the subsequent deprotection are not compatible in the presence of the selone function. As a solution to this problem, we used 2-phenylallyl groups for $N$-protection. ${ }^{[24]}$ As a first model synthesis imidazole was bis-alkylated with phenylallyl bromide $\mathbf{1}$ (Figure $1 \mathrm{~b}$ ). The resulting $\mathrm{N}, \mathrm{N}$-alkyl imidazolium was reacted with a weak base and elemental selenium to produce selone $\mathbf{2}$ in $53 \%$ yield. Treatment of 2 with tert-butyl lithium allowed efficient removal of the phenylallyl groups to produce selenoimidazole which oxidized to the symmetric diselenide 3 ( $94 \%$ yield). Similar procedures were used to synthesize the diselenides 8 - 11, including the isologs of lactoperoxidase and thyroid peroxidase (10), ${ }^{[23 c,}$, 23d, 25] and known mercaptoimidazole-based inhibitors of lipoxygenase (11). ${ }^{[26]}$

The synthesis of selenoneine was started with protection of the primary amine of $L$-histidine methyl ester 12 with tertbutyloxycarbonyl to give 13 (Scheme 1). Using the aforementioned phenylallyl protection, 13 was converted to selone 14. Deprotection of $\mathbf{1 4}$ gave the diselenide 15 in racemic form, as inferred by polarimetry. Removal of the Bocprotecting group under acidic conditions, followed by reductive amination with formaldehyde gave dimethylamine 16 in $53 \%$ yield over two steps. 16 was reduced and then reacted with ethyl chloroformate to give 17. Methylation with methyl iodide gave 18. Treatment of this compound with $\mathrm{LiOH} . \mathrm{H}_{2} \mathrm{O}$ produced selenoneine, which was isolated as diselenide 19 in $2 \%$ yield (120 mg) over 11 steps.

In a next step we started to characterize the properties of synthetic selenoneine. As noted before selenoneine readily oxidizes to a stable diselenide. ${ }^{[27]}$ In contrast, ergothioneine is largely resistant towards autooxidation and the symmetric disulfide slowly decomposes by hydrolysis at neutral $\mathrm{pH}^{[28]}$ The proton NMR spectra recorded of selenoneine and ergothioneine in buffered solutions at $\mathrm{pH}$ between 6 and 13 show that both molecules are characterized by a single deprotonation event at alkaline $\mathrm{pH}\left(\mathrm{p} K_{\mathrm{a}, \mathrm{sel}}=10.1, \mathrm{p} K_{\mathrm{a}, \mathrm{erg}}=10.6\right.$, published $\left.p K_{a, e r g}=10.8\right)^{[29]}$, suggesting that both molecules are neutral under physiological conditions (Figure S1). This finding establishes that the higher propensity of selenoneine for oxidative dimerization is not due to higher acidity.

The structural and electrostatic similarity of selenoneine and ergothioneine suggest that selenoneine could be an efficient substrate for the human ergothioneine transporter (ETTh). ${ }^{[30]}$ To test this idea, the ETTh was expressed and assayed in human embryonic kidney 293 cells as established previously (Supporting information) ${ }^{[31]}$ Briefly, adherent cells were incubated shortly with selenoneine at $37{ }^{\circ} \mathrm{C}$ in a chemically defined buffer. After washing and cell lysis, the selenoneine content was determined by Liquid Chromatography-Mass Spectrometry (LC-MS/MS). Uptake of selenoneine was saturable (Figure S2), with a $K_{M}$ of $27(95 \%$ confidence interval, 16-46) $\mu \mathrm{mol} / \mathrm{L}$. Similar $K_{\mathrm{M}}$ values were reported previously for ergothioneine and the ETT transporters from human $(21(16-28) \mu \mathrm{M}),{ }^{[30]} \mathrm{pig}(22(12-39) \mu \mathrm{mol} / \mathrm{L})$, and chicken $(11(8-17) \mu \mathrm{mol} / \mathrm{L}){ }^{\left[{ }^{[32]}\right.}$ In the particular experiment shown, with a $V_{\max }$ of 560 (standard error, \pm 32 ) pmol min-1 $\mathrm{mg}$ protein $^{-1}$, the clearance $\left(V_{\max } / K_{\mathrm{M}}\right.$, a measure of transport 
efficiency) was $21 \mu \mathrm{L} \mathrm{min}{ }^{-1} \mathrm{mg}$ protein ${ }^{-1}$, somewhat lower than typically measured (i.e. $50-100 \mu \mathrm{L} \mathrm{min}^{-1} \mathrm{mg}$ protein ${ }^{-1}$ ) for ergothioneine and ETTh in our expression system. Nevertheless these data support the idea that selenoneine is efficiently distributed in the human body even at low concentrations. ${ }^{[17 a, 19]}$

An earlier study examined selenoneine uptake using the diselenide form, and quantified uptake indirectly by Inductively Coupled Plasma Mass Spectrometry (ICP-MS), using total selenium content as a proxy. ${ }^{[17 a]}$ This experiment raised the possibility that the diselenide instead of or in addition to the reduced form might be a substrate for the ETTh. To test this possibility, we prepared a redox-stable analogue of selenoneine diselenide by linking two selones with a single methylene group (20, Scheme 1). Accumulation of this compound (incubation time $1 \mathrm{~min}, 1 \mu \mathrm{M}$ and $10 \mu \mathrm{M}$ ) in ETTexpressing cells was not higher than in control cells (not shown). By contrast, uptake of ergothioneine (1 min, $10 \mu \mathrm{M})$ measured in paired dishes was 30 -fold higher in ETTexpressing cells than in control cells. Thus, we conclude that ETTh cannot efficiently transport $\mathbf{2 0}$. This finding underscores the strict substrate specificity of ETTh and establishes that selenoneine is transported in reduced form. ${ }^{[31]}$ Most likely, the complex cell culture medium used in the previous uptake experiments contained sufficient free thiols $(>30 \mu \mathrm{M})$ to reduce all or a fraction of the diselenide. Similarly, the extracellular plasma contains a considerable pool of free thiols $(\sim 0.4-0.6$ $\mathrm{mM}$, mostly Cys34 on human serum albumin) that may account for the efficient uptake of selenoneine in the human body. ${ }^{[33]}$

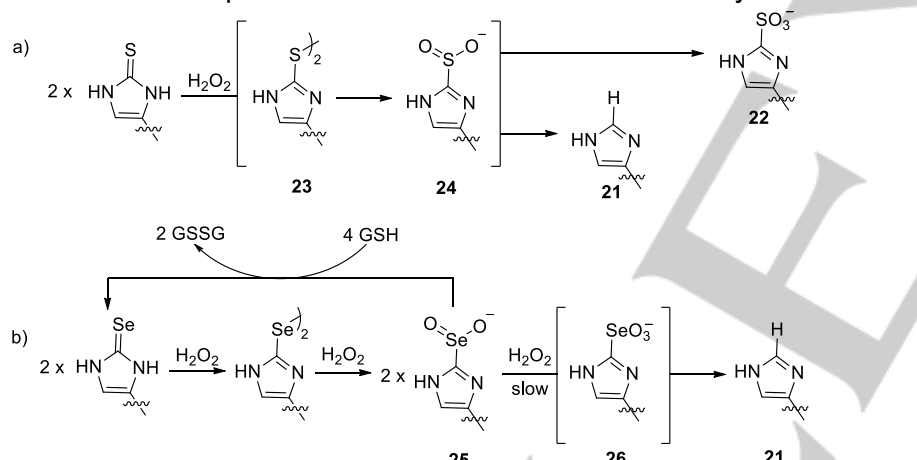

Scheme 2. Reactions of ergothioneine (a) and selenoneine (b) with $\mathrm{H}_{2} \mathrm{O}_{2}$

A final set of experiments were designed to compare the redox reactivity of selenoneine and ergothioneine. The consensus opinion in the literature posits that ergothioneine protects cells from oxidative stress. ${ }^{[34]}$ One way to decipher the mechanisms of ergothioneine-based cytoprotection is to study the redox reactivity of ergothioneine and its oxidation products. ${ }^{[28 a, 35]}$ Treatment with reactive oxygen species such as hydrogen peroxide and superoxide was shown to convert ergothioneine to TMH (21, Scheme 2, Figure S3) or ergothioneine sulfonic acid (22). Both metabolites have been isolated from biological samples, indicating that oxidative degradation of ergothioneine is a physiologically relevant process. ${ }^{[34 \mathrm{~d}]}$ The intermediate oxidation products ergothioneine disulphide (23) and ergothioneine sulfinic acid (24) are less stable and do not accumulate. ${ }^{[28 a]}$ Selenoneine shows a very different behaviour. Conditions that completely desulfurize ergothioneine, convert selenoneine to the stable seleninic acid (25, Figure S4). The same product emerges from a reaction of hydrogen peroxide with selenoneine diselenide, suggesting that the diselenide is an intermediate in the formation of seleninic acid. Deselenation of the seleninic acid was observed as a slow and hydrogen peroxide dependent reaction (rate: [3 $\pm 1] \times 10^{-3} \mathrm{~min}^{-1}$ ), suggesting that further oxidation to the unstable selenonic acid (26) is a prerequisite for $\mathrm{C}$-Se bond cleavage.

On the other hand, 25 reacts rapidly and quantitatively with GSH or DTT to reform selenoneine (Figure S4). ${ }^{[36]}$ This reactivity suggest that in a cellular context reductive recycling of $\mathbf{2 5}$ is much more efficient than deselenation. Consequently, selenoneine is more resistant towards irreversible oxidative degradation than ergothioneine. Indeed, resistance towards oxidative deselenation has been suggested as the main evolutionary incentive for replacement of specific sulfur atoms with selenium in proteins, nucleic acids and - as exemplified by selenoneine - in secondary metabolites. ${ }^{[37]}$

Under aerobic conditions and in the absence of reducing equivalents the most stable form of selenoneine is the diselenide 19. ${ }^{[16,20 \mathrm{~b}]}$ Based on the report that selenenyl sulfides and seleninic acids react with electron-rich arenes via electrophilic aromatic substitution, ${ }^{[38]}$ we wondered as to whether selenoneine diselenide would react in a similar way. Indeed, incubation of selenoneine diselenide with resorcinol in a buffered aqueous solution at $37^{\circ} \mathrm{C}$ for $24 \mathrm{~h}$ readily produced a selenoneine adduct of resorcinol (27, Figure S5). Although resorcinol is not itself a known natural product, 1,3benzenediol motifs are common among phenylpropanoids, terpenoids, polyketides and nonribosomal peptides. Therefore, it is possible that a broad range of selenoneine adducts of natural products may have yet to be discovered from natural sources. To provide a few explicit examples we reacted the phenylpropanoid resveratrol, the nonribosomal peptide vancomycin and polyketide proansamitocin ${ }^{[39]}$ with selenoneine diselenide to produce the corresponding adducts (28 - 30, Figure 2). 
WILEY-VCH

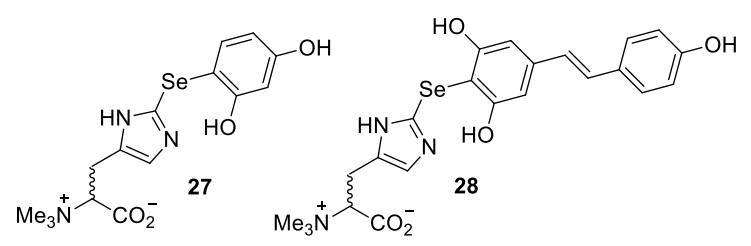

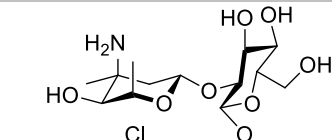

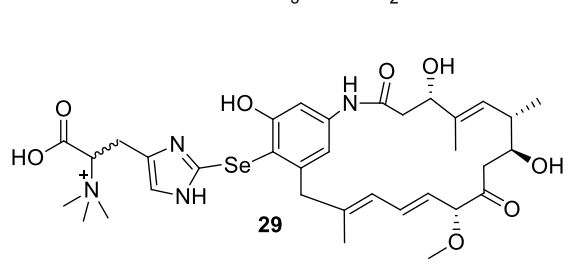

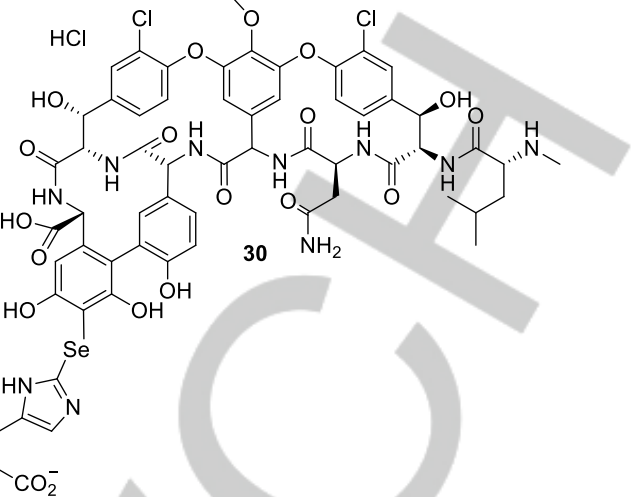

Figure 2. Reactivity of selenoneine diselenide with $\mathrm{C}$-nucleophiles. Reaction conditions: Selenoneine diselenide $(0.2-1 \mathrm{mM})$, arene $(4-10 \mathrm{mM}), 0.1 \mathrm{M}$ Tris (pH 8$)$, $\mathrm{H}_{2} \mathrm{O}$ or $\mathrm{H}_{2} \mathrm{O} / \mathrm{EtOH}(9: 1), 37^{\circ} \mathrm{C}, 24 \mathrm{~h}$. Products were identified by HR-ESI-MS. Yields were determined by HPLC peak integration (27: $89 \%$; 28: 86 \%; $29: 87 \%$; 30 : $5 \%)$.

Conclusions. In this report we describe a general method for the synthesis of $\mathrm{N}$-alkylated and unalkylated 2selenoimidazoles. We demonstrated that synthetic selenoneine is imported by human cells with similar efficiency as ergothioneine. Selenoneine was shown to engage in reversible oxidation and reduction reaction under conditions that irreversibly degrade ergothioneine. These findings suggest that selenoneine is a more robust antioxidant than ergothioneine. Selenoneine diselenide was shown to react with complex natural products via electrophilic aromatic substitution to form selenoneine adducts. These reactions occur under physiological conditions raising the possibility that adduct formation may be part of selenoneines functional portfolio. The different reactivities of selenoneine and ergothioneine support the idea that the two compounds fill distinct functional niches in biology.

\section{Acknowledgements}

We thank Friederike Schäkel and Andreas Kirschning for providing a sample of proansamitocin and Samira Boussettaoui and Simone Kalis for skilful technical assistance. This project was supported by a starting grant from the European Research Council (ERC-2013- StG 336559), the NCCR for Molecular Systems Engineering and by the "Professur für Molekulare Bionik".

Keywords: 2-selenoimidazole $\cdot$ antioxidant $\bullet$ organoselenide - natural product $\cdot$ ergothioneine

[1] aM. Roman, P. Jitaru, C. Barbante, Metallomics 2014, 6, 25-54; bM Birringer, S. Pilawa, L. Flohé, Nat Prod Rep. 2002, 19, $693-718 ; \mathrm{cH}$. J. Reich, R. J. Hondal, ACS Chem Biol. 2016, 11, 821841.

[2] C. Arnaudguilhem, K. Bierla, L. Ouerdane, H. Preud'homme, A. Yiannikouris, R. Lobinski, Anal Chim Acta. 2012, 757, 26 - 38.

[3] P. J. White, Ann Bot. 2016, 117, 217 - 235.

[4] aN. Metanis, D. Hilvert, Curr Opin Chem Biol. 2014, 22, 27 - 34; bW. T. Self, in Comprehensive Natural Products II, Vol. 5 (Eds.: H. W. Liu, L. Mander), Elsevier Science, 2010, pp. 121 - 148.

[5] T. Nauser, D. Steinmann, W. H. Koppenol, Amino Acids 2012, 42, 39 44.

[6] G. W. r. Luther, A. J. Findlay, D. J. Macdonald, S. M. Owings, T. E. Hanson, R. A. Beinart, P. R. Girguis, Front. Microbiol. 2011, 2, 1-9.

[7] J. Beld, K. J. Woycechowsky, D. Hilvert, Biochemistry 2007, 46, 5382 5390
[8] aN. Metanis, D. Hilvert, Angew Chem Int Ed Eng/ 2012, 51, 5585 5588; bJ. Liu, F. Zheng, R. Cheng, S. Li, S. Rozovsky, Q. Wang, L. Wang, J. Am. Chem. Soc. 2018, 140, 8807 - 8816.

[9] J. H. Palmer, G. Parkin, Polyhedron 2013, 52, 658-668.

[10] aR. Mousa, R. Notis Dardashti, N. Metanis, Angew Chem Int Ed Engl. 2017, 56, 15818 - 15827; bA. C. Conibear, E. E. Watson, R. J. Payne, C. F. W. Becker, Chem Soc Rev. 2018, 47, 9046 - 9068.

[11] aD. Wu, L. Chen, N. Kwon, J. Yoon, Chem 2016, 1, 674 - 698; bM. Abdo, S. Liu, B. Zhou, C. D. Walls, L. Wu, S. Knapp, Z. Y. Zhang, J. Am. Chem. Soc. 2008, 130, 13196 - 13197; cZ. Chen, Z. Jiang, N. Chen, Q. Shi, L. Tong, F. Kong, X. Cheng, H. Chen, C. Wang, B. Tang, Chem Commun 2018, 54, 9506 - 9509.

[12] aN. V. Barbosa, C. W. Nogueira, P. A. Nogara, A. F. de Bem, M. Aschner, J. B. T. Rocha, Metallomics 2017, 9, 1703 - 1734; bN. Noguchi, Arch Biochem Biophys. 2016, 595, 109 - 112; cG. Mugesh, W. W. du Mont, H. Sies, Chem. Rev. 2001, 101, 2125 - 2179; dK. N. Sands, T. A. Tuck, T. G. Back, Chemistry 2018, 24, 9714 - 9728; eC. W. Nogueira, J. B. Rocha, Arch Toxicol. 2011, 85, 1313 - 1359.

[13] aJ. Kil, E. Lobarinas, C. Spankovich, S. K. Griffiths, P. J. Antonelli, E. D. Lynch, C. G. Le Prell, Lancet. 2017, 390, 969 - 979; bN. Singh, A C. Halliday, J. M. Thomas, O. V. Kuznetsova, R. Baldwin, E. C. Woon, P. K. Aley, I. Antoniadou, T. Sharp, S. R. Vasudevan, G. C. Churchill, Nat. Commun 2013, 4; cS. Thenin-Houssier, I. M. de Vera, L. PedroRosa, A. Brady, A. Richard, B. Konnick, S. Opp, C. Buffone, J. Fuhrmann, S. Kota, B. Billack, M. Pietka-Ottlik, T. Tellinghuisen, H. Choe, T. Spicer, L. Scampavia, F. Diaz-Griffero, D. J. Kojetin, S. T. Valente, Antimicrob Agents Chemother. 2016, 60, 2195 - 2208; dT. Yamaguchi, K. Sano, K. Takakura, I. Saito, Y. Shinohara, T. Asano, H. Yasuhara, Stroke 1998, 29, 12 - 17; eM. Kalayci, O. Coskun, F. Cagavi, M. Kanter, F. Armutcu, S. Gul, B. Acikgoz, Neurochem Res. 2005, 30, $403-410$.

[14] R. Alhasan, M. J. Nasim, C. Jacob, c. Gaucher, Curr Pharmacol Rep 2019, 5, $163-173$.

[15] Y. Yamashita, T. Yabu, M. Yamashita, World J Biol Chem 2010, 1, 144-150.

[16] M. Yamashita, Y. Yamashita, T. Ando, J. Wakamiya, S. Akiba, Biol Trace Elem Res 2013, 156, 36-44.

[17] aM. Yamashita, Y. Y., T. Suzuki, Y. Kani, N. Mizusawa, S. Imamura K. Takemoto, T. Hara, M. A. Hossain, T. Yabu, K. Touhata, Mar. Biotechnol. 2013, 15, 559 - 570; bM. P. Rayman, Lancet 2012, 379, 1256 - 1268; cJ. Masuda, C. Umemura, M. Yokozawa, K. Yamauchi, T. Seko, M. Yamashita, Y. Yamashita, Nutrients 2018, 10, E1380; dA. S. Rahmanto, M. J. Davies, IUBMB Life 2012, 64, 863 - 871.

[18] J. H. Palmer, G. Parkin, J. Am. Chem. Soc. 2015, 137, 4503 4516.

[19] I. Rohn, N. Kroepfl, J. Bornhorst, D. Kuehnelt, T. Schwerdtle, Mol Nutr Food Res. 2019, 63.

[20] aT. Pluskal, M. Ueno, M. Yanagida, PLoS One 2014, 9, e97774; bN. G. Turrini, N. Kroepfl, K. B. Jensen, T. C. Reiter, K. A. Francesconi, T. Schwerdtle, W. Kroutil, D. Kuehnelt, Metallomics 2018, 10, 1532 1538.

[21] aM. Garner, D. R. Armstrong, J. Reglinski, W. E. Smith, R. Wilson, J. H. McKillop, Bioorganic \& Medicinal Chemistry Letters 1994, 4, 1357-1360; bS. Benvenuti, F. Severi, G. Vampa, L. Malmusi, L. Antolini, Journal of Heterocyclic Chemistry 1995, 32, 1613-1619; cE. S. Raper, J. R. Creighton, R. E. Oughtred, I. W. Nowell, Acta Crystallographica Section B Structural Science 1983, 39, 355-360; dE. E. Simanek, A. Tsoi, C. C. C. Wang, G. M. Whitesides, M. T. McBride, G. T. R. Palmore, Chemistry of Materials 1997, 9, 1954-1961; el. 
Erdelmeier, S. Daunay, R Lebel L. Farescour, J-C. Yadan, Green Chemistry 2012, 14, 2256; fJ. Xu, J. C. Yadan, The Journal of Organic Chemistry 1995, 60, 6296-6301; gP. L. Khonde, A. Jardine, Org Biomol Chem 2015, 13, 1415-1419; hH. Heath, A. Lawson, C. Rimington, Nature 1950, 166, 106-106.

[22] J. Bezencon, M. B. Wittwer, B. Cutting, M. Smiesko, B. Wagner, M. Kansy, B. Ernst, J Pharm Biomed Anal 2014, 93, 147-155.

[23] aS. Yadav, R. Deka, H. B. Singh, Chemistry Letters 2019, 48, 6579; bV. K. Landry, M. Minoura, K. Pang, D. Buccella, B. V. Kelly, G. Parkin, J Am Chem Soc 2006, 128, 12490-12497; cG. Roy, G. Mugesh, J Am Chem Soc 2005, 127, 15207-15217; dP. N. Jayaram, G. Roy, G. Mugesh, Journal of Chemical Sciences 2008, 120, 143-154.

[24] J. Barluenga, F. J. Fananas, R. Sanz, C. Marcos, J. M. Ignacio, Chem Commun (Camb) 2005, 933-935.

[25] D. Manna, G. Roy, G. Mugesh, Acc Chem Res. 2013, 46, 2706 2715.

[26] A. Assadieskandar, M. Amini, M. Salehi, H. Sadeghian, M. Alimardani, A. Sakhteman, H. Nadri, A. Shafiee, Bioorg Med Chem 2012, 20, 7160-7166.

[27] Y. Yamashita, M. Yamashita, J Biol Chem 2010, 285, 18134-18138.

[28] aL. Servillo, D. Castaldo, R. Casale, N. D'Onofrio, A. Giovane, D. Cautela, M. L. Balestrieri, Free Radic. Biol. Med. 2015, 79, 228 - 236; bT. G. HEATH H, Biochem. J. 1958, 68, 204 - 210.

[29] J. Carlsson, M. P. J. Kierstan, K. Brocklehurst, Biochemical Journal 1974, 139, 221-235

[30] D. Gründemann, S. Harlfinger, S. Golz, A. Geerts, A. Lazar, R. Berkels, N. Jung, A. Rubbert, E. Schoemig, Proc. Natl. Acad. Sci. U. S A. 2005, 102, 5256-5261.

[31] J. Tschirka, M. Kreisor, J. Betz, D. Gründemann, Drug Metab Dispos. 2018, 46, 779 - 785

[32] D. Nikodemus, D. Lazic, M. Bach, T. Bauer, C. Pfeiffer, L. Wiltzer, E. Lain, E. Schömig, D. Gründemann, J Physiol Pharmacol. 2011, 62, $411-419$.

[33] L. Turell, R. Radi, B. Alvarez, Free Radic Biol Med. 2013, 65.

[34] aB. Halliwell, I. K. Cheah, R. M. Y. Tang, FEBS Lett. 2018, 592 3357 - 3366; bB. N. Ames, Proc Natl Acad Sci U S A. 2018, 115, 10836 - 10844; cB. M. Cumming, K. C. Chinta, V. P. Reddy, A. J. C. Steyn, Antioxid. Redox Signal. 2018, 28, 431 - 444; dL. Servillo, N. D'Onofrio, M. L. Balestrieri, J Cardiovasc Pharmacol. 2017, 69, 183 - 191.

[35] M. Oumari, B. Goldfuss, C. Stoffels, H. G. Schmalz, D. Gründemann, Free Radic Biol Med. 2019, 134, 498 - 504

[36] J. L. Kice, T. W. S. Lee, J. Am. Chem. Soc. 1978, 100, 5094 - 5102.

[37] al. M. Bell, M. L. Fisher, Z. P. Wu, D. Hilvert, Biochemistry 1993, 32 3754 - 3762; bN. C. Payne, A. Geissler, A. Button, A. R. Sasuclark, A. L. Schroll, E. L. Ruggles, V. N. Gladyshev, R. J. Hondal, Free Radic Biol Med. 2017, 104, 249 - 261.

[38] aD. T. Cohen, C. Zhang, C. M. Fadzen, A. J. Mijalis, L. Hie, K. D. Johnson, Z. Shriver, O. Plante, S. J. Miller, S. L. Buchwald, B. L. Pentelute, Nat Chem 2019, 11, 78-85; bM. Abdo, S. Knapp, J. Am. Chem. Soc. 2008, 130, 9234 - 9235.

[39] S. Eichner, T. Knobloch, H. G. Floss, J. Fohrer, K. Harmrolfs, J. Hermane, A. Schulz, F. Sasse, P. Spiteller, F. Taft, A. Kirschning, Angew Chem Int Ed Engl. 2012, 51, 752 - 757. 
Entry for the Table of Contents (Please choose one layout)

Layout 1:

\section{COMMUNICATION}

Text for Table of Contents
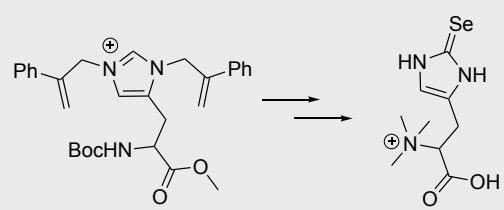

David Lim, Dirk Gründemann and Florian P. Seebeck ${ }^{*}$

Page No. - Page No.

Total synthesis and characterization of Selenoneine 